\title{
Protecting Legal and Illegal Voluntary On-Road Collectors
}

\author{
Kenn Beer, Tom Bowrey, Tom Beer \\ Safe System Solutions Pty Ltd G2, Brunswick, VIC, Australia \\ Email: kenn.beer@safesystemsolutions.com.au, tom.bowrey@safesystemsolutions.com.au, \\ *tom.beer@safesystemsolutions.com.au
}

How to cite this paper: Beer, K., Bowrey, T. and Beer, T. (2021) Protecting Legal and Illegal Voluntary On-Road Collectors. Open Journal of Safety Science and Technology, 11, 1-11.

https://doi.org/10.4236/ojsst.2021.111001

Received: January 7, 2021

Accepted: March 19, 2021

Published: March 22, 2021

Copyright $\odot 2021$ by author(s) and Scientific Research Publishing Inc. This work is licensed under the Creative Commons Attribution International License (CC BY 4.0).

http://creativecommons.org/licenses/by/4.0/

\section{(c) (i) Open Access}

\begin{abstract}
The health community uses a harm reduction model that deals with harm reduction at four levels: conceptual, practical, policy, and programmatic. The road safety community has adopted the Safe System as their harm reduction model. The Safe System is underpinned by the key principles: people make mistakes, the human body has limited biomechanical tolerance, there is a shared responsibility for creating a safer system and we aspire for zero death and serious injury in transport. The interacting elements/levers to achieve these principles are road and roadsides (infrastructure), safe people, safe vehicles, and safe speeds. Using on-road collectors as a specific example, the relationship between the health-based harm reduction model and the Safe System reveals that the Safe System assumes the conceptual, practical and policy levels to be pre-determined, and thus restricts itself to the programmatic level of the health-based harm reduction model.
\end{abstract}

\section{Keywords}

Harm Reduction, Safe System, On-Road Activities, Road Safety

\section{Introduction}

Subrule 4 of rule 236 of the Australian Road Rules states that:

A pedestrian must not stand on, or move onto, a road to:

1) solicit contributions, employment or business from an occupant of a vehicle; or
2) hitchhike; or
3) display an advertisement, or
4) sell or offer articles for sale; or
5) wash or clean, or offer to wash or clean, the windscreen of a vehicle. 
Despite the fact that all jurisdictions in Australia, except for the Australian Capital Territory (ACT), make these activities illegal without a permit, they are prevalent on many roads in Australian cities.

While windscreen washing (Figure 1) is considered the dominant activity, other activities are becoming more commonplace around Australia, including intersection entertainers, sellers and other collectors including charity collectors. We will use the term on-road collector as a generic term to cover all such activities.

Even in places where the activities are legal, or where a permit has been issued to enable them to take place, they are inherently unsafe because of the proximity of a vulnerable pedestrian (the on-road collector) to vehicles that may move at substantial speeds.

There is substantial evidence that the risk of serious injury or fatality as a result of a vehicle collision increases markedly with speed. For unprotected individuals (vulnerable road users) such as pedestrians or cyclists, the probability of a fatality rises markedly if they are struck by a vehicle travelling above $30 \mathrm{~km} / \mathrm{h}$, and a fatality is virtually certain to occur if such an unprotected individual is struck by a vehicle travelling above $60 \mathrm{~km} / \mathrm{h}$ as shown in Figure 2.

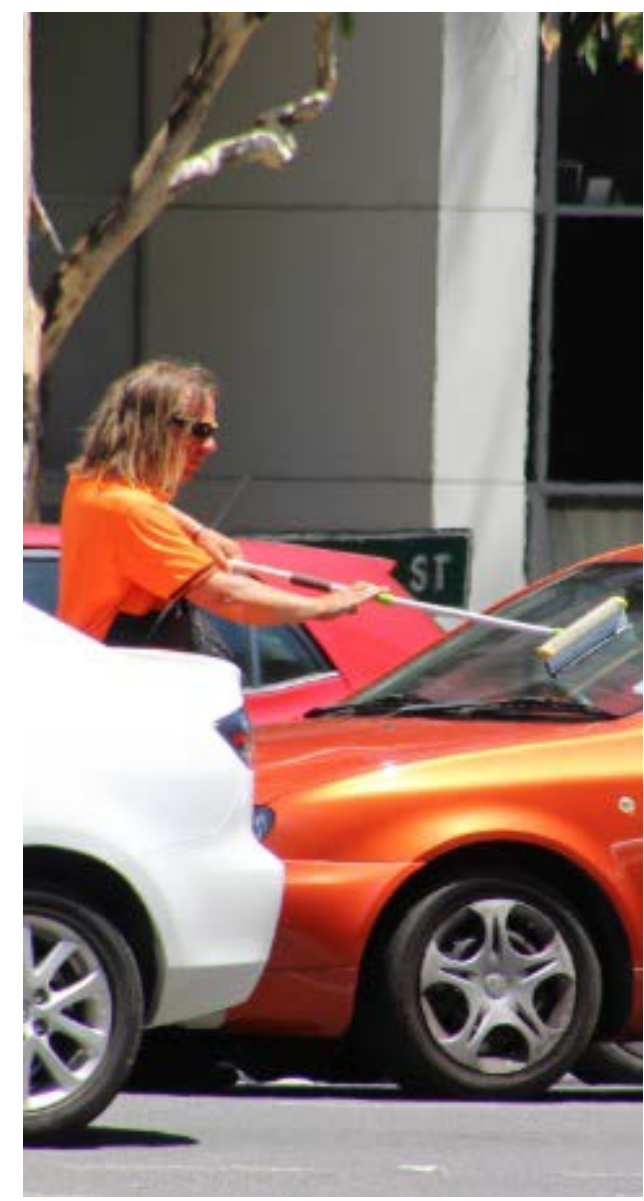

Figure 1. Windscreen washer Northbourne Avenue/Barry Drive, ACT. 


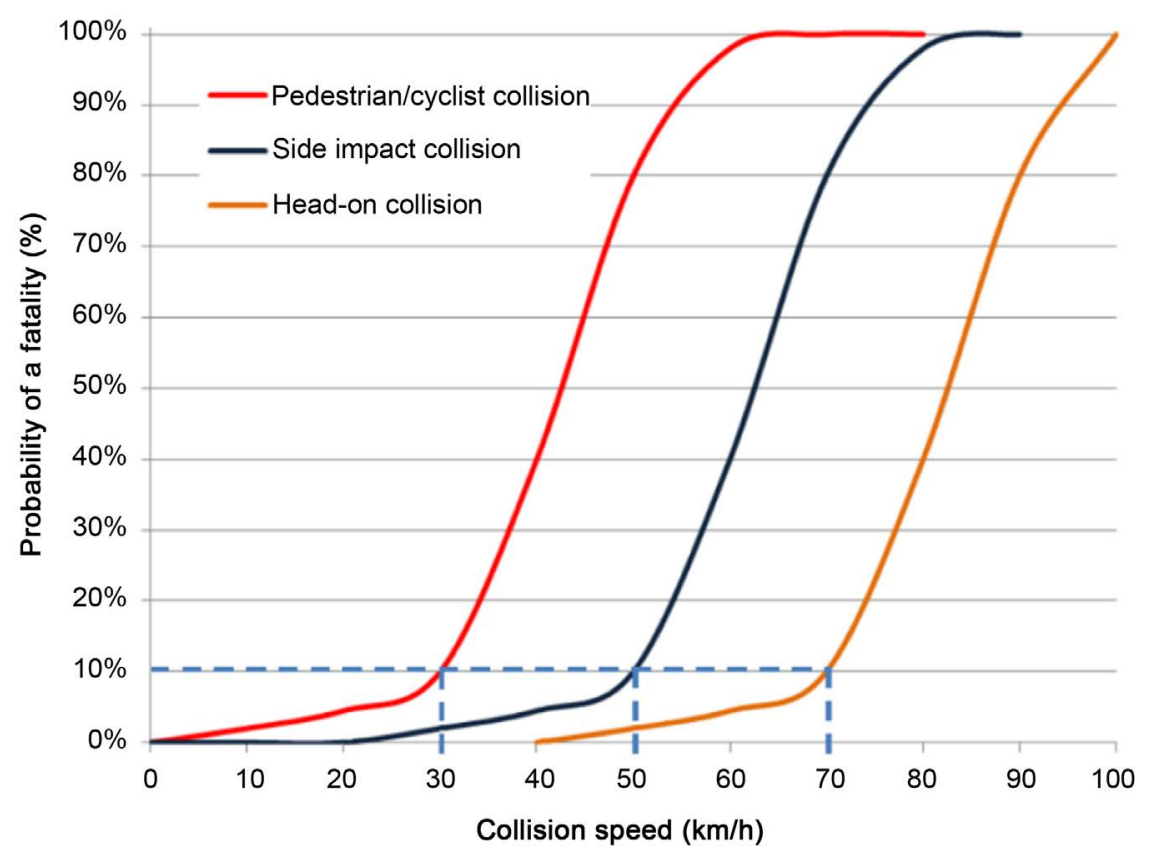

Figure 2. The probability of a fatality for a pedestrian struck by a vehicle increases markedly above $30 \mathrm{~km} / \mathrm{h}$.

The risks arise both from a direct impact, when the on-road collector is directly struck by a vehicle, and also from secondary impacts when vehicle collisions result in an unexpected impact with the on-road collector.

There is a good understanding of the risk of injury to pedestrians if struck by a passenger car [1]. One should aspire to interaction speeds of no more than 30 $\mathrm{km} / \mathrm{h}$ because at or below these speeds harm outcomes become substantially less likely. The inter-relationship between infrastructure and speed is, therefore, a critical consideration. This requires that emphasis be placed on the value of roads additional to their value as conduits for traffic movements. This assists in providing a pragmatic and realistic approach towards achieving environments that are not hostile to pedestrians. As a general rule, separation of pedestrians and vehicles, or risk reduction treatments that support a very low speed environment for motor vehicles are currently the best means for harm reduction that achieve road safety outcomes.

Analysis of pedestrian collisions [2] showed that one quarter of coroner-examined deaths involved alcohol and one third involved drugs. Most casualties occurred in urban areas (95\%), in lower-speed zones (78\%). It is assumed that such analysis is applicable to on-road collectors.

\section{Methods}

This paper seeks to determine whether the Harm Reduction Model of [3], shown in Figure 3, can be applied to protect on-road collectors and, if so, to determine how it interacts with the Safe System framework that is generally used for harm reduction within the road safety community [4]. Though at first sight it may 


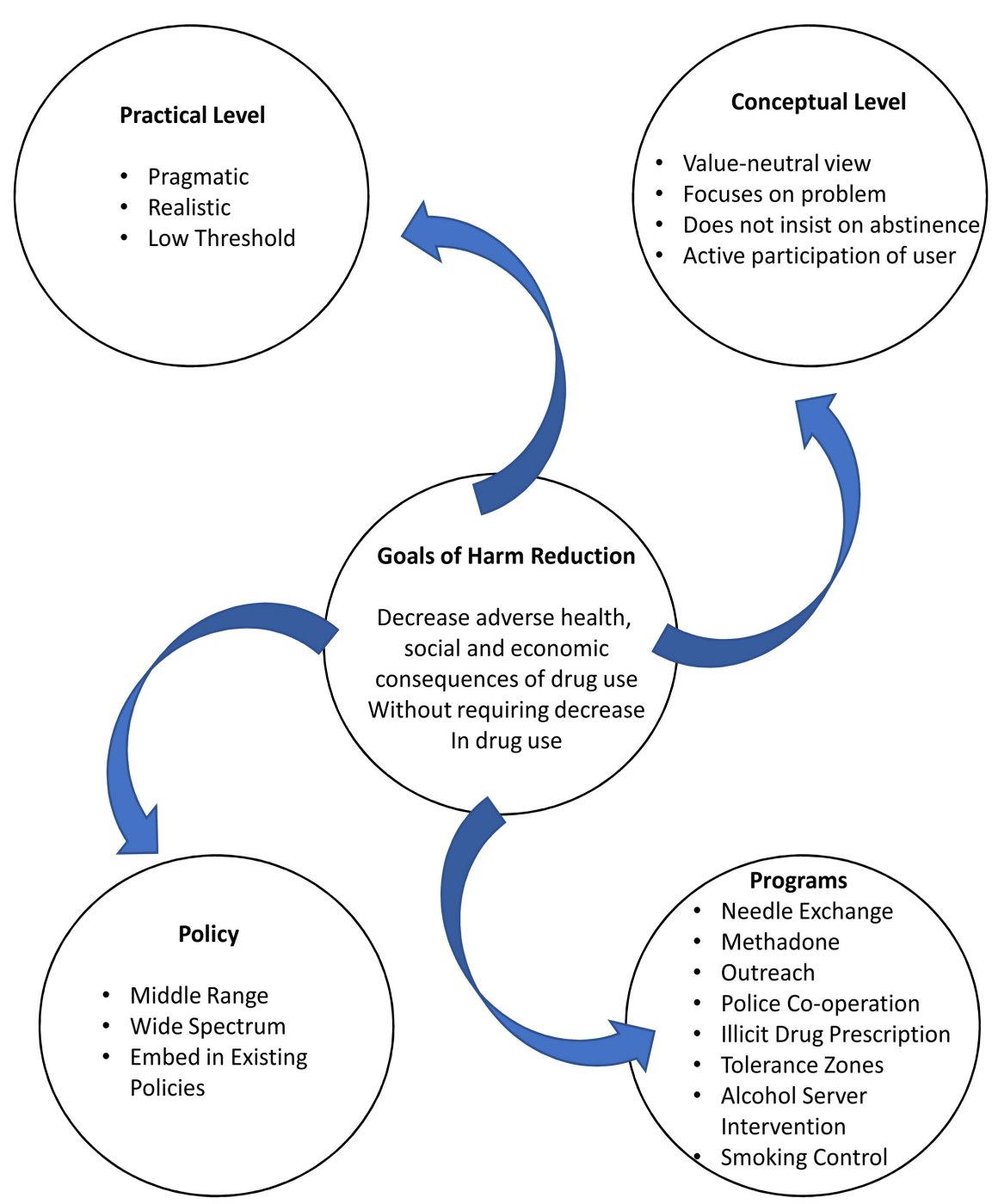

Figure 3. The harm reduction model [3].

seem curious to try to apply a model that is used to decrease the adverse health consequences of substance abuse, primarily illicit drug use, to on-road collectors, there is a certain analogy between the two. In both cases, the person is undertaking voluntary risky behaviour though it may be argued that the economic consequences differ. In the case of substance abuse, the activity costs the user money. In the case of on-road collection, in most cases the goal is to make money-either for the collectors themselves, or for any charity for which they may be collecting. It is straightforward to reword the Goals of Harm Reduction, shown in Figure 3, to the on-road collector as: "Decrease adverse health and social consequences of on-road collection without requiring a decrease in on-road collection".

By examining 30 road intersections within the ACT, the only Australian jurisdiction in which on-road collecting is legal, the applicability of the Harm Reduction Model and its compatibility to the Safe System were determined. This led to a list of policies and programs to ensure the safety of the on-road collectors. 
This section examines the four headings shown in Figure 3-namely Conceptual Level, Practical Level, Policy and Programs.

\subsection{Conceptual Level}

The conceptual level highlights the similarities between societal treatment of illicit substance abusers and on-road collectors. They are both against the law in Australia (except for the ACT where on-line collection has been legalised). Our harm reduction framework focuses on the problems that they face and seeks solutions at the program level. We do not seek abstinence. In an extension of the conceptual level we do seek active participation of the collector (to help to protect themselves) but also active participation of the authorities to help to protect them.

\subsection{Practical Level}

Once one accepts the conceptual level view of the protection, rather than the banning, of on-road collectors, then one seeks pragmatic solutions that are realistic. The term "low-threshold" is used to describe those services that do not impose abstinence from substance abuse as a condition of service access; and endeavour to reduce other documented barriers to service access. Within the context of on-road collection it refers to solutions that impose minimal disruption to the on-road collection activities-for example, wearing a safety vest while engaged in on-road collection would be a low threshold solution.

\subsection{Policy}

At the policy level harm reduction generates a patchwork quilt of middle-range policy measures that match a wide spectrum of patterns that can sometimes be accommodated by the existing larger policy framework. In the case of on-road collectors, the existing larger policy framework is that of the Safe System.

The Safe System seeks to eliminate death and serious injury on roads. It consists of four elements: safe roads, safe speeds, safe vehicles, and safe people. The philosophy has been adopted by road authorities in Australia under a host of different names that often emphasise the elimination of fatalities and serious injuries. In Victoria, for example, the policy is called Towards Zero with the Safe System providing the framework for the policy. At the national level there is a Vision Zero that examines more than just road safety by seeking to ensure that all accidents, diseases and harm at work are preventable.

\subsection{Programs}

Safe System Assessment (SSA) is a tool to convert Safe System principles into practice. A SSA is an examination of an existing length of road or intersection or a proposed infrastructure project to assess the extent to which existing conditions, or proposed projects, align with Safe System principles, specifically, in eliminating fatal and serious injury crashes. Guidance on conducting SSAs is in 
[4] and [5].

Thirty sites in the ACT were examined to gain an understanding of different intersection layouts for intersections that are, or may in the future be, popular for on-road collectors. Nine criteria were used for site-selection: 1) Traffic signal operated intersections; 2) Large to medium multi-lane intersections; 3) A mix of dual carriageway and single carriageway; 4) Cross intersections and T-intersections; 5) A variety of signal phasings; 6) Both single and multiple right turn lanes; 7) Slip lanes present and not present; 8) Dividing islands painted or physical 9) Long to medium traffic signal cycle times.

The primary focus was on windscreen washers-people that wash the windscreens of cars queued at traffic signals and then hope to be paid for their work as shown in Figure 1.

On the basis of the inspection and a Safe System Assessment, the potentially hazardous activities of on-road collecting were identified and classified according to the following five elements:

1) Windscreen Washer Struck By Passenger Vehicle (Car) - 4 Sub Categories.

a) While waiting in the median.

b) While washing a car windscreen and traffic is stopped.

c) While crossing the carriageway to access another approach to the intersection (or when accessing or egressing the site).

d) While stranded in between vehicles moving through the intersection.

2) Windscreen Washer Struck By Other Vehicles-4 Sub Categories.

a) Motorcycle/scooter.

b) Cyclists.

c) Buses.

d) Commercial Vehicles.

3) Crashes Between Other Road Users Because Of Windscreen Washers-4 Sub Categories.

a) Lane change crash/side swipe crash.

b) Pedestrian (other than windscreen washer).

c) Cross traffic or right against intersection crash.

d) Rear end.

In case there were specific issues for different categories of on-road collectors, the next element specifically examined the four most common categories of on-road collectors after windscreen washers.

4) Other On-Road Activities-4 Sub Categories.

a) Highway Collectors.

b) Intersection entertainers.

c) Advertisers.

d) Hitchhikers.

5) Future Road Use-2 Sub Categories.

a) Metropolitan Light Rail.

b) Cycling infrastructure. 
An example is shown in Figure 4 in relation to "crossing the carriageway to access another approach to the intersection (or when accessing or egressing the site)" which is subcategory 1c of Windscreen Washer Struck By Passenger Vehicle (Car). For each element and subcategory the assessment considers whether, under likely crash scenarios, the transfer of kinetic energy to the human would be below levels causing death or serious injury. For road user behaviour elements the Table identifies activities currently being undertaken, and recommends project activities that could improve the safe use of the road.

The activity shown in Figure 4 is deemed to be non-safe system compliant because during the inspection on-road collectors, windscreen washers in this case, crossed carriageways to access waiting traffic at an adjacent approach to the intersection. The behaviour was observed to be in front of approaching traffic. Though some vehicle speeds were observed as lower than $30 \mathrm{~km} / \mathrm{h}$ because they were accelerating from the red-light phase, some vehicles were observed at speeds considered sufficient to cause serious injury or fatality. These cars were approaching a relatively clear intersection as the lights changed to green and thus had the ability to continue through at their approach speed.

\begin{tabular}{|c|c|c|c|c|}
\hline ELEMENT & $\begin{array}{c}\text { PRIMARY } \\
\text { TREATMENT - SAFE } \\
\text { SYSTEM } \\
\text { COMPLIANT }\end{array}$ & $\begin{array}{l}\text { STEP TOWARDS } \\
\text { SAFE SYSTEM }\end{array}$ & $\begin{array}{l}\text { SAFE SYSTEM } \\
\text { SUPPORTING } \\
\text { TREATMENTS }\end{array}$ & $\begin{array}{c}\text { NON SAFE SYSTEM } \\
\text { COMPLIANT }\end{array}$ \\
\hline $\begin{array}{l}\text { While crossing the carriageway to access } \\
\text { another approach to the intersection (or when } \\
\text { accessing or egressing the site) }\end{array}$ & $\begin{array}{l}\text { Implement measures } \\
\text { to reduce the travel } \\
\text { speed of vehicles } \\
\text { through the intersec- } \\
\text { tion to } 30 \mathrm{~km} / \mathrm{h} \text { or } \\
\text { below. } \\
\text { Possible measures } \\
\text { include: } \\
\text { - Regulatory speed } \\
\text { limit reductions } \\
\text { backed up with } \\
\quad \text { enforcement } \\
\text { Raised safety } \\
\text { platforms } \\
\text { designed for } 30 \\
\text { km/h travel } \\
\text { speeds } \\
\text { Alternatively, eliminate } \\
\text { the activity or confine it } \\
\text { to areas of speeds } \\
\text { lower than } 30 \mathrm{~km} / \mathrm{h} \text {. }\end{array}$ & $\begin{array}{l}\text { Implement measures } \\
\text { to reduce the travel } \\
\text { speed of vehicles } \\
\text { through the intersec- } \\
\text { tion to } 40 \text { - } 50 \mathrm{~km} / \mathrm{h} \text {. } \\
\text { While this will not meet } \\
\text { Primary Safe System } \\
\text { principles, it will sig- } \\
\text { nificantly reduce the } \\
\text { probability of a crash, } \\
\text { and in some circum- } \\
\text { stances will reduce the } \\
\text { severity of the crash } \\
\text { to within tolerable } \\
\text { levels. Possible } \\
\text { measures include: } \\
\text { - Regulatory speed } \\
\text { limit reductions } \\
\text { backed up with } \\
\text { enforcement } \\
\quad \text { Raised safety } \\
\text { platforms } \\
\text { designed for } \\
40 \text { - } 50 \mathrm{~km} / \mathrm{h} \\
\text { travel speeds }\end{array}$ & $\begin{array}{l}\text { Facilities that will } \\
\text { reduce the risk of } \\
\text { crashes with the } \\
\text { windscreen washers, } \\
\text { but not "virtually } \\
\text { eliminate" the risk are: } \\
\text { - Warning signs } \\
\text { (active or static) } \\
\text { Clear sight lines } \\
\text { to the } \\
\text { approaching } \\
\text { intersection } \\
\text { Street lighting } \\
\text { (although most of } \\
\text { the sites reviewed } \\
\text { had adequate } \\
\text { street lighting) } \\
\text { Ensuring the } \\
\text { windscreen } \\
\text { washers are } \\
\text { wearing highly } \\
\text { visible clothing } \\
\text { Changing the } \\
\text { traffic signal } \\
\text { phasing to re- } \\
\text { move the conflict } \\
\text { (noting that it still } \\
\text { may occur by a } \\
\text { red light runner) } \\
\text { Other methods to } \\
\text { alert drivers to the } \\
\text { presence of the } \\
\text { window washers }\end{array}$ & $\begin{array}{l}\text { During the Audit } \\
\text { inspection the } \\
\text { Auditors witnessed } \\
\text { windscreen } \\
\text { washers crossing } \\
\text { carriageways to } \\
\text { access waiting traffic } \\
\text { at an adjacent } \\
\text { approach to the } \\
\text { intersection. The } \\
\text { behaviour was } \\
\text { front of approaching } \\
\text { traffic. } \\
\text { While some vehicle } \\
\text { speeds were ob- } \\
\text { served as lower than } \\
30 \text { km/h because } \\
\text { they were accelerat- } \\
\text { ing from the red light } \\
\text { phase, some vehicles } \\
\text { were observed at } \\
\text { speeds considered } \\
\text { sufficient to cause } \\
\text { serious injury or } \\
\text { fatality. These were } \\
\text { cars that were ap- } \\
\text { proaching a relatively } \\
\text { clear intersection as } \\
\text { the lights changed to } \\
\text { green and having the } \\
\text { ability to continue } \\
\text { through at their } \\
\text { approach speed. }\end{array}$ \\
\hline
\end{tabular}

Figure 4. The results of the inspection are presented in a manner that provides recommendations for improved alignment with the harm reduction intent of Safe System principles illustrating treatments needed to support, partially implement, or fully implement Safe System principles. 
Figure 4 lists the steps that would be needed to provide Safe System supporting treatments. It also lists the steps that would be needed to move the activity towards a Safe System. These are given in columns 4 and 3 respectively. Column 2 lists the steps needed to undertake primary treatment and to make this activity Safe System compliant. These are to "implement measures to reduce the travel speed of vehicles through the intersection to $30 \mathrm{~km} / \mathrm{h}$ or below". Possible measures include:

- Regulatory speed limit reductions backed up with enforcement.

- Raised safety platforms designed for $30 \mathrm{~km} / \mathrm{h}$ travel speeds.

The assessment also provides the advantages and disadvantages of such measures. Thus, for example, Figure 5 shows the advice in relation to raised safety platforms.

\section{Results}

Harm reduction measures focused on the potential for high energy crashes between windscreen washers and cars; windscreen washers and motorcycles; windscreen washers and commercial vehicles; and vehicle-to-vehicle crashes. Within the Harm Reduction Model of Figure 3, identified Programs were grouped under the four elements of the Safe System.

\subsection{Safe Roads}

Infrastructure measures to improve the alignment with Safe System principles include raised intersections or raised safety platforms; Implementation of "Squeegee Zones" as areas in which these activities are to be confined; Audible warning of imminent signal phase changes; Speed limit reductions; Pelican style signal displays (i.e. yellow flashing phase included in the sequence); Passive or active warning signs; Adapted Pedestrian User Friendly Intelligent (PUFFIN) Crossings; Flagged washing areas; Protection with roadside barriers; Limiting these activities to intersections with lower risk.

\subsection{Safe Speeds}

An analysis of the existing speed limits, predicted operating speeds and possible

\begin{tabular}{|c|c|c|c|}
\hline Idea & Effectiveness & Safety System Alignmen & Comments \\
\hline 1. Raised safety platforms or raised intersections at popular intersections & High & Primary/Step Towards & $\begin{array}{l}\text { Advantages: } \\
\text { - Will reduce the risk significantly regardless of windscreen } \\
\text { washer behavior } \\
\text { - Address the significant crash risk at large intersections } \\
\text { for vehicle to vehicle crashes } \\
\text { - Has high alignment with Safe System principles } \\
\text { - Does not reply on the windscreen washer complying with } \\
\text { regulations } \\
\text { - Has been implemented in other jurisdictions and countries. } \\
\text { Disadvantages: } \\
\text { - May disrupt/annoy people travelling through these major } \\
\text { arterials } \\
\text { - Needs to be carefully designed for buses and heavy vehicles. }\end{array}$ \\
\hline
\end{tabular}

Figure 5. Detailed advice on how to implement raised safety platforms. 


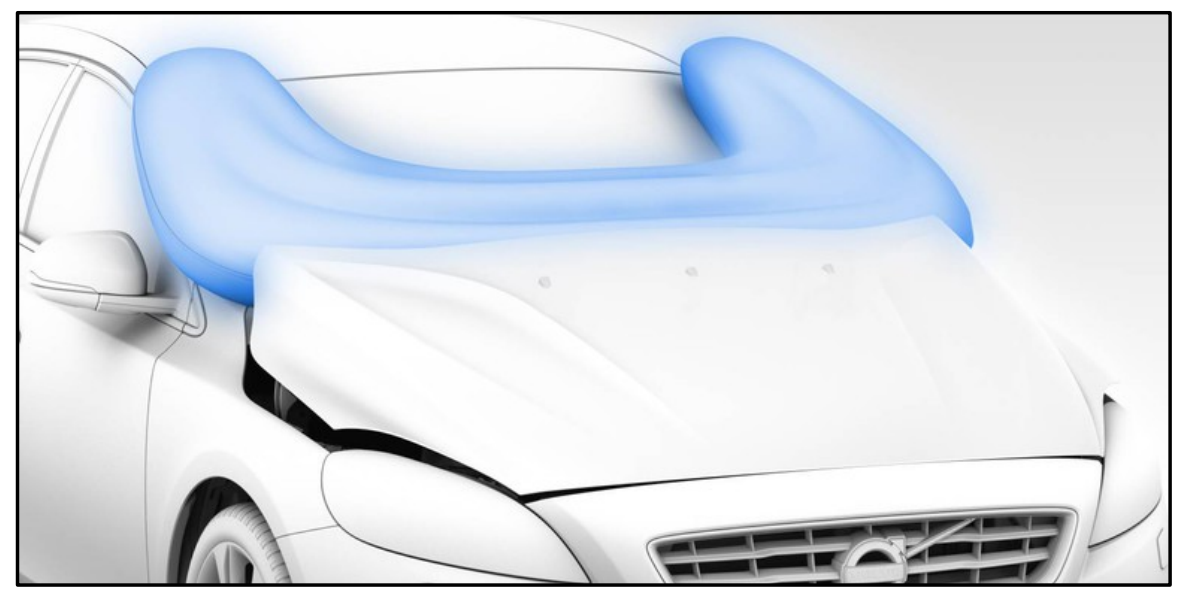

Figure 6. Artist's impression of Volvo's pedestrian airbags.

speed limits were undertaken. The majority of popular intersections were currently signed as $60 \mathrm{~km} / \mathrm{h}$ with predicted free travel operating speed above 60 $\mathrm{km} / \mathrm{h}$. It is noted that $60 \mathrm{~km} / \mathrm{h}$ is above the Safe System speed tolerable for a collision with a Vulnerable Road User.

\subsection{Safe People}

After analysis of behavioural aspects of on-road collecting and other intersection activities the following recommendations were made: Educate and enforce existing illegal movements/activities where there is no possibility of minimising the danger; Install CCTV cameras at key intersections; Seek opportunities to run training or information sessions with known windscreen washers or others using intersections as a method of revenue generation; Get advice from a psychologist as to an appropriate age for being involved in these activities. Implement actions to minimise the risk of young community members undertaking these activities; Continue with campaigns and behavioural change initiatives to reduce the occurrence of driving while fatigued; In association with other recommended activities, investigate whether drug and alcohol support is required for anyone undertaking windscreen washing or other on-road collection at intersections; Continue with drug/alcohol and driving behavioural change programs and enforcement; Promote the public's ability to call 000 when inappropriate behaviour occurs; Ensure that popular intersections are well lit, and that any training or information highlights the dangers of undertaking these activities at night or in fog conditions; Work with a social enterprise organisation such as The Big Issue to provide windscreen washers with reflective vests.

\subsection{Safe Vehicles}

A number of systems have been developed to reduce the severity of head injuries when a pedestrian is struck by a car. These include pedestrian airbags (Figure 6) and active pop-up bonnets that are activated when sensors in the car's front bumper detect a leg strike, as distinct from another vehicle or a fixed object. 
Regardless of the type of system, the reduction in injuries is premised upon the same principle: a reduction of impact forces from the vehicle to the pedestrian by increasing the deformable distance.

In the case of a pop-up bonnet system, the bonnet sheet metal is raised away from the unyielding mechanical parts under the bonnet, and this gap allows a degree of cushioning to the pedestrian's head upon impact.

The Pedestrian Airbag (Figure 6), first brought to market in 2012, augments the pop-up bonnet by also providing coverage beyond the bonnet sheet metal, typically at the base of the windscreen and around the windscreen framework.

In the light of the type of vehicles presently using Australian roads, and the expected transition to future vehicles-some of which may be autonomous vehicles, it was recommended that the authorities consult and collaborate with manufacturers and users of vehicle technologies to ensure compatibility between permitted activities and pedestrian air-bag systems and with future deployed Autonomous Vehicle systems.

\section{Discussion}

The health-directed harm reduction model can be used within the road safety context to identify and treat possible harm to individuals, such as on-road collectors, that is a result of their own voluntary activities. This has been recognised in the road safety sphere since 2005 when a harm reduction framework was applied to determine appropriate speed limits for roads [6]. In this case, harm reduction was again based on Vision Zero, and it was noted that in Vision Zero terminology, crash energy must not exceed the biomechanical tolerance of humans. One consequence of this requirement is that transport in the road environment should not be undertaken at speeds where in the event of a crash, the release of kinetic energy proves to be above what the human body can stand without incurring a serious or fatal injury.

The overlap between harm reduction and the Safe System approach to road safety has also been recognised in more recent work. The harm reduction approach implies that planning, road design and traffic management need to consider how to reduce the severity of crashes when they occur along with the traditional, conventional engineering approaches. Reference [1] notes that:

... the understanding of what lies behind road user error is evolving but it is evident that many of the situations people are placed in when using the road system invite certain errors to be made. We now understand that many of these errors cannot be easily eliminated. Furthermore, system designers and managers have a responsibility to not only mitigate for predictable errors but also protect those innocently caught up in crashes. The appropriate response to dealing with this issue is to ensure that the road network is forgiving of error and does not allow people to inadvertently cause harm.

\section{Conclusions}

Australian jurisdictions consider on-road collecting to be an activity that is suf- 
ficiently harmful that it is legally permitted in only one territory, the ACT, though other States will allow it in particular instances upon application for a permit. Such permits are primarily issued for on-road collecting for recognised charities.

Analysis of pedestrian collisions [2] showed that one quarter of coroner-examined deaths involved alcohol and one third involved drugs. Most casualties occurred in urban areas (95\%), in lower-speed zones (78\%). If it is assumed that such analysis is applicable to on-road collectors then it becomes possible to target programs specifically for their harm reduction [7].

In the more general case, it is necessary to use generalised harm reduction models, of which the Safe System is the one most applicable to road safety [8]. The Safe System may be considered to be a road-specific application of the general harm reduction model [3].

\section{Acknowledgements}

Safe System Solutions Pty Ltd was engaged by the ACT Government to undertake a Full Safe System Assessment of some of the most known and busiest windscreen washing locations in the ACT. This paper is an outcome of this work and we acknowledge the assistance of the ACT Government.

\section{Conflicts of Interest}

The authors declare no conflicts of interest regarding the publication of this paper.

\section{References}

[1] Woolley, J., Stokes, C., Turner, B. and Jurewicz, C. (2018) Towards Safe System Infrastructure: A Compendium of Current Knowledge. Austroads Report. AP-R560-18, Austroads, Sydney.

[2] Senserrick, T., Boufous, S., de Rome, L., Ivers, R. and Stevenson, M. (2014) Detailed Analysis of Pedestrian Casualty Collisions in Victoria, Australia. Traffic Injury Prevention, 15, S197-S205. https://doi.org/10.1080/15389588.2014.935356

[3] Cheung, Y.W. (2000) Substance Abuse and Developments in Harm Reduction. Canadian Medical Association Journal, 162, 1697-1700.

[4] Turner, B., Jurewicz, C., Pratt, K., Corben, B. and Woolley, J. (2016) Safe System Assessment Framework. Austroads Report AP-R509-16, Austroads, Sydney.

[5] VicRoads (2018) Safe System Assessment Guidelines.

[6] Austroads (2005) Balance between Harm Reduction and Mobility in Setting Speed Limits: A Feasibility Study. AP-R272-05, Austroads, Sydney, NSW.

[7] Islam, M.M., Topp, L., Conigrave, K.M. and Day, C. (2013). Defining a Service for People Who Use Drugs as 'Low-Threshold': What Should be the Criteria? International Journal of Drug Policy, 24, 220-222.

https://doi.org/10.1016/j.drugpo.2013.03.005

[8] Austroads (2017) Safe System Infrastructure for Mixed Use Arterial Roads. Technical Report AP-T330-17, Austroads, Sydney, NSW. 